\title{
Monoclonal Antibody AbGn-7
}

National Cancer Institute

\section{Source}

National Cancer Institute. Monoclonal Antibody AbGn-7. NCI Thesaurus. Code C99162.

A chimeric monoclonal antibody against a Lewis-A-like glycotope (AbGn-7 antigen) with potential immunomodulating and antineoplastic activities. Monoclonal antibody AbGn-7 targets and binds to the carbohydrate AbGn-7 antigen on the cell surface of tumor cells and may induce complement-dependent cytotoxicity (CDC) and antibody-dependent cellmediated cytotoxicity (ADCC), thereby killing AbGn-7-epitope positive tumor cells. AbGn-7 antigen is expressed on a variety of tumor cell types, including human colorectal, pancreatic and gastric tumor cells. 